in the $10,000 \mathrm{~m}$ event. Over $100 \mathrm{~m}$ and $400 \mathrm{~m}$ but not over $200 \mathrm{~m}$ the times at altitude were better than at sealevel.

By interpolation on this graph the predicted increase in time taken for a race lasting $6 \mathrm{~min}$ would be about 8 per cent, which agrees well with the results predicted from maximum exercise tests referred to here which were of this duration.

National Institute for Medical Research,

$$
\text { L. G. C. E. Pugh }
$$

Division of Human Physiology,

c/o Medical Research Council Laboratories,

Holly Hill, London, N.W.3.

${ }^{1}$ Pugh, L. G. C. E., Gill, M. B., Lahiri, S., Milledge, J. S., Ward, M. P., and West, J. B., J. App, Physiol., 19, 431 (1964).

2 United States 19.56 Olympic Book, edit. by Bushnell, A. S., and Lentz, A. G. (U.S. Olympic Association, New York, 1957).

\section{Response of the Medial Rectus Muscle of the Cat to Succinylcholine}

IN contrast to its relaxing action on most skeletal muscles, succinylcholine is well known to contract extraocular muscles ${ }^{1-3}$. While examining the effects of drugs on the extra-ocular muscles, it was observed that succinylcholine exerted two basically different effects on the extra-ocular muscles.

Cats were anaesthetized with sodium pentobarbital $(36 \mathrm{mg} / \mathrm{kg}$ ) given by intraperitoneal injection. The trachea, femoral artery and femoral vein were cannulated and artificial respiration started. The medial rectus muscle of the left eye was then separated from the globe and a suture placed through the tendon. Following immobilization of the animal's head in a stereotaxic apparatus, the tendon was attached to a Grass force displacement transducer. Through a parietal craniotomy, the dura mater was opened and the left cerebral hemisphere lifted gently to expose the third nerve. Electrical stimulation of the third nerve was affected by impaling the exposed nerve with a needle electrode delivering supramaximal rectangular pulses, $0.5 \mathrm{msec}$ duration at a frequency of $0.3 \mathrm{c} / \mathrm{s}$.

The intravenous injection of small doses of succinylcholine (less than $10 \mu \mathrm{g} / \mathrm{kg}$ ) resulted in an increase in the resting tension of the medial rectus muscle associated with an increase in the twitch height. However, large doses of succinylcholine $(30-150 \mu \mathrm{g} / \mathrm{kg})$ produced a marked increase in resting tension as well as a severe reduction of the twitch response. This reduction in the twitch response was unrelated to the rise in resting tension. A typical example of this response to larger doses of succinylcholine is shown in Fig. 1. It can be seen that inhibition of the twitch persists at a time when the tension of the muscle is returning to normal. In a given animal, the smallest dose of succinylcholine required to depress the twitch height, with respect to the control, was approximately ten times greater than the smallest dose required to increase the resting tension of the muscle.

These different pharmacological responses of the extra-ocular muscles to succinylcholine may be explained by the anatomical observations of Hess ${ }^{4}$ and Hess and Pilar $^{5}$. These authors reported two types of neuro-

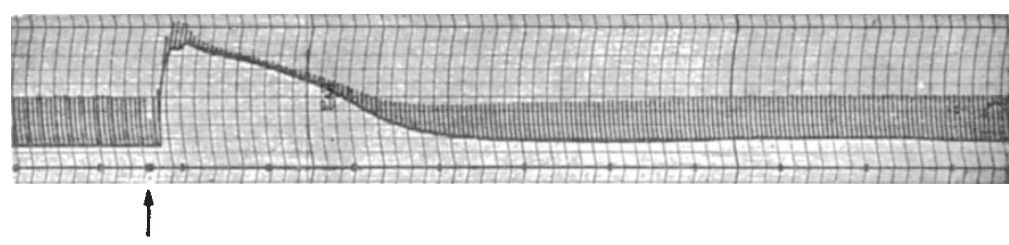

Fig. 1. Effect of suceinylcholine on the medial rectus muscle of the cat. At arrow, $64 \mu \mathrm{g} / \mathrm{kg}$ succinylcholine was given intravenously. Note marked rise in resting tension and depression of twitch response Maximum increase in baseline occurred prior to maximum depression of the twitch response. One min between signal markers muscular systems to be present in the extra-ocular muscles of the cat; a fast or twitch system, and a slow or tonic system. It would, therefore, seem reasonable to attribute the increased muscle tension seen after the intravenous injection of succinylcholine to stimulation of the tonic system, and depression of the twitch response to blockade of the fast neuromuscular system.

By means of the preparation described in this report, it is possible simultaneously to compare and contrast the effect of drugs in vivo on the two contractile systems present in the extra-ocular muscles of the cat.

This work was supported by a grant-in-aid $(G-303)$ from the U.S. National Council to Combat Blindness, Now York, and grant $G M-09069-03$ from the U.S. National Institutes of Health.

\section{KENNETH E. EAKINS}

RONALD L. KaTZ

Departments of Anaesthesiology,

Ophthalmology and Pharmacology,

College of Physicians and Surgeons, Columbia University, New York.

${ }^{1}$ Hofnann, H., and Lembeck, F., Arch. Exp. Path. Pharmacol., 216, 552 (1952)

${ }^{2}$ Lincoff, H. A., Breinin, G. M., and De Voe, A. E., Amer. J. Ophthat., 43, $440(1957)$

Macri, F. J., and Grimes, P. A., Amer. J. Ophthal., 44, 221 (1957)

Hess, A., Rev. Canad. Biol., 21, 241 (1962).

${ }^{5}$ Hess, A., and Pilar, G., J. Physiol. (Lond.), 169, 780 (1963).

\section{Membrane Potentials in Longitudinal Smooth Muscle isolated from Guinea-pig Ileum}

THE activity of the smooth muscle in guinea-pig ileum has been investigated many times. The tissue preparation most often used for such investigations has boen the isolated ileum. In a number of cases, however, experiments have been carried out, not with the whole ileum, but with the thin outer layer of longitudinal smooth muscle that can be easily separated from the ileum ${ }^{1-8}$. This communication provides a brief description of membrane potentials which occur in this isolated muscle preparation. The work arose from an interest in correlating electrical activity with the transmembrane movements of potassium ion and the mechanical responses of the muscle that have been examined previously. It was desirable, therefore, to explore the fersibility of estimating changes in electrical activity in this preparation.

Membrane potentials were measured by means of the sucrose gap method ${ }^{4,5}$. An isotonic solution of potassium chloride flowed over an inactive portion of the muscle; and a physiological salt solution, over an active portion of the muscle. The composition of the physiological salt solution was: $\mathrm{NaCl}, 0.125 \mathrm{M} ; \mathrm{KCl}, 0.0027 \mathrm{M} ; \mathrm{CaCl}_{2}$, $0.0018 \mathrm{M}$; $\mathrm{NaHCO}_{3}, 0.024 \mathrm{M}$; and glucose, $0.011 \mathrm{M}$. The solution was saturated with a gas mixture consisting of 95 per cent oxygen and 5 per cent carbon dioxide. The temperature was maintained between $35^{\circ} \mathrm{C}$ and $37^{\circ} \mathrm{C}$.

Potentials of unexcited muscle. Sections of longitudinal muscle, placed in a sucrose gap apparatus through which the aforementioned solutions flowed, exhibited changes in membrane potentials that are illustrated in Fig. 1. The development of simple, spiked depolarizations which varied in amplitude and frequency were common occurrences. Moreover, each spike was usually preceded by a slower, more prolonged decrease in membrane potential. The slow depolarizations had the appearance of pre-potentials that, possibly, trigger subsequent spikes. Slow depolarizations also preceded more complex membrane changes in which two or more spiked depolarizations were generated before the membrane potential returned to base- 